\title{
Philosophic Discourse Language and Transcendence: Hermeneutic Nature
}

\author{
Sergey Bredikhin ${ }^{1, *}$, and Liana Vartanova ${ }^{2}$ \\ ${ }^{1}$ North-Caucasus Federal University, Department of Theory and practice of Translation, 355000 Stavropol', Russia
}

\begin{abstract}
The article views the phenomenon of philosophizing as a specific type of discourse, which uses the metalanguage of the third level of abstraction to verbalize the process of thinking. The research proves that the phenomenon of the translated philosophic text also appears to be the metascientific discourse of the reflection over the ontological and over its verbalization. The revealing of noematic hierarchy of sense bearing structures is necessary for the pure hermeneutical understanding of the philosophic text sense. The analysis shows that the new sense derivation and interpretation turns into a process of overflow and mutations that pervades the entire cognitive sphere.
\end{abstract}

\section{Introduction}

The central issue of recent studies in a sense derivation process is exploring semiotic and cultural aspects of the text derivation. In this article we shall consider a philosophic language phenomenon as a special variant of a language that verbalizes thinking, and it is the definition of language given by Jaspers that is the main proposition in the present study: "This transcending thinking is such a thinking, which is sciencial in its nature due to the method, and at the same time is different from the scientific cognition because of absence of the certain subject" [1].

\section{Materials and Methods}

In this paper, we discuss the possibility of a new approach to the analysis of philosophic sense derivation when conceptualizing ideas. The sense superconstruction is considered as a hierarchical structure of the intentional relevant noems, as the smallest quanta of multidenominational sense. We are trying to describe the principles of phenomenological and noematic reflection as the basis for sense-decoding, interpretation and derivation. Sense derivation models are closely connected with the use of correct intent techniques for phenomenological philological reflection verbalized in signs and symbols / linguistic units, texts - mental constructs. All this causes the birth of proto- and metasense, new formation of the semantic structure of the philosophic text, text creation within and beyond understanding. We have called a new methodological approach as "philological phenomenological hermeneutics", which is an attempt to organize a methodological apparatus of cognitive linguistics, phenomenology and hermeneutics, and build a more coherent concept of sense.

According to Jaspers, philosophy is not static by nature, and so is the language of philosophic discourse: Philosophy and philosophic discourse texts are scientific by their methodology, but are scientifically different. The science is generally meant to be a discourse, or rather a kind of discourse.

Philosophy is also often defined as a discourse - the phrase "the philosophic discourse" has already become quite widespread [2].

Philosophy presents the metascientific discourse as a reflection over the ontological and the statement verbalization of it. It is not just a trivial cognition of the objective reality; philosophy is more profound than any other cognition subject, it is targeted to the essence, in particular the essence of a verbalizing component. Being understood as the transcending thinking, philosophy is also supposed to be the transcending verbal expression, as Jaspers remarks, "One can say that philosophic explanation succeeds when the thing becomes nonfigurative, and in double sense it consists in the fact that a positivist has nothing left as he can not see the subject any longer, whereas it gives the insight to the philosopher. He can not, however, comprehend the true existence in disappearing of the subject, but is able to be full of it" [1]. Besides, philosophizing transcends not the thinking subject itself, or rather not only it, but also the discourse, as well as the text, verbalizing the concept of a phenomenon. The discourse retains definite segments of the objective reality as well as reflection areas, but philosophic text distinguishes meanings and the existence in the space of the text reality; thus destructing somehow the discourse.

Verbalization of the ontological constructs faces the insoluble contradiction: the existence and the thought

* Corresponding author: bredichinsergey@yandex.ru 
about it can not be represented in the discourse, but philosophizing is the discourse itself, or, as some scientists label it, "pseudo discourse". Standard language does not give this opportunity, which results in creating new metalanguage of philosophy that is often paradoxical and makes it possible to express thinking "on the verge of language and beyond it". Diversity of discourses and the discourse itself can take place due to the presence of some primary transcendence flow that is not a discourse in its usual interpretation, but it gives rise to a type of a metadiscourse that allows retaining and destructing other types of discourse. The flow of discourse play, in the view of the linguists, is the matter special to the linguistic interpretation that represents philosophizing. Philosophic discourse simulates other discourse types and reflects both over them and their language, but it is not the specific discourse by itself. Possessing some special features, it is an attempt to verbalize reflexive thinking acts in their pure form on the third abstraction level "the line of disappearing and levelling of all discourse structures so that to release the pure entitative flow" [3]. For example, Heidegger's philosophy goes back to the discourse - the discourse of daily routine as the main existence sphere Dasein (an untrue existence). This discourse undergoes the destructive analysis (Dasein analytics) in order to disclose an ecstatic temporality as a basic line of any existence comprehension.

According to A. Bergson's observation, intuitive origin underlies any philosophizing. It is this intuitive constant that makes the main subject of the philosopher's work. It is often impossible to verbalize it, and the debate of its origin and the way to represent it is the work of philosophers (here we also take into consideration an intentiality constant in relation to the given definition the "intuitive"). And even realizing this intuitively, we can not clarify the understood or the realized, but generate the comprehension; it is a certain way to clarify the prelanguage existence and sometimes even the premeaning, a certain attraction centre, a singularity point.

"To decode the meaning of a philosophic text, we should in fact trace its way of creating the meaning. Apparently, it can not be entirely feasible, as the philosopher himself tries to verbalize this original intention in all his papers" [4]. However, in Bergson's opinion this intention should meet the requirements of the recipient's rational logic; therefore, both the meaning and the immanent intention should be decodable. Thus, by decoding a philosophic doctrine (a conception that is actually the representation of intuition), we approach the central point of philosophizing, and this very doctrine is communicatively oriented, while the intuition is not communicative in its essence, but it is a non-reflective alien experience. Here is the difference between the interpretation of the philosophic text and the philosopher's comprehension; it is rooted both in the relation to the philosopher's language and to the recipient's one. Intentional "failures" in verbalization of intuitive pre-experienced phenomenon should not interfere with the hermeneutical act of comprehension; on the contrary, they should mark the definite comprehension schemes. The philosopher moves from intuition to verbalization and communication, whereas the recipient indispensably determines the meanings immanently presented in the text and represented in the language phenomena. A qualitative leap in thinking is essential for this operation, and, while generating the text meaning, the recipient's reflection does not matter less than the philosopher's one.

An enormous gap between the thing intuitively being realized and the verbalized in a philosophical text is the incomprehension, on which the thought is based: it is the main factor of the phenomenological reflection formation. For any philosophic doctrine, regardless of a school it belongs to, it is important to reflect not only over the considered phenomena, but also over the language used by the philosopher. "The language of philosophy is paradoxical; it has to do with the thing that is impossible to know in any way" [5].

The idea about the primary philosophic issue stands out in all M. Heidegger's works. Any ontological discussion is subjected to the language transcendence. "The clash of the language and the objective reality, the clash and the academic argument of a thing or a word as its sign is significant discussion of the «Dasein» matters with respect to the components «Da» and «Sein» of the presence opposition in a chronotop (Befindlichkeit) and the hermeneutic process of comprehension and realization of the presence (Verstehen)" [4].

It is of a certain interest to transfer to the essence of philosophizing as the original intuitive, without addressing to the types of verbalization. Here we would deal with the technical attitude to the language: and for the hermeneutic comprehension of a philosopher's language, the analysis of the derivation mechanisms of the sense is the inevitable charge preceding the genuine vision of the point. The choice of the means of verbalization, i. e. the language of philosophizing itself, can or can't be adequate and successful, unlike the intuition constant, which stands out and is separated from the language means, though it gives a chance to feel the presence of the producer of the philosophic text; respectively, a verbalized text of the theory or the conception is the mean of the comprehension.

They say that the language of the German philosophy differs from other languages, even from the language of philosophy in other countries, in particular from the English one. Many texts of the German philosophers were translated into other languages, but the matter concerns a frequently inadequate compromise between the observance of the original and the interpreted reading. In this case we deal not with the translation problem and the lack of translation alternation, but with the main problems of the hermeneutic sense. What's the translation, the individual, the author's or the secondary creation of the sense? The matter about the parallel and sometimes interpenetrative influence of the translation and the sense creation is obvious. It is, probably, related to the fact that a text of the translation, being a result of the translation process, at the same time serves as a certain and mediated mark with a foreign form of the secondary text in respect to the author's sense creation; thus being a fixed and unique field in the text of the 
recipient-language for investigating possibilities of the sense creation in both languages. Different techniques of the discourse analysis are worth mentioning in the process of transferring the objectivity of all sense types, as they can provide additional criteria of the adequacy. In this paragraph we make an attempt to represent our opinion on the general correlation of ideas and a process of the sense creation in translation and also about the significance of the lingocultural approach that, as we concern, can play an integrating role in the translation and the sense creation process studying; and if we succeed, we shall suggest an additional criterion of adequacy while translating multidirectional discourses.

One can affirm that at least two approaches to the mentioned problem do exist: the translation as the secondary sense creation on basis of a text of the language-object and the author's sense creation as an interpretative processing of the «foreign» conceptual sphere itself. «The first prototype undervalues the factor of the language difference and the specific character of the transfer from one language into the other with the fixation of the transfer results in the form of the translation text and, correspondently, equates the translation and the interpretation. Whereas, the second prototype overestimates the difference factor of personal intellectual codes and thus equates the interpretation and the translation» $[6]$.

In the first case, the creation of a certain version for the original text becomes natural, thus distorting the meaning of the notion «sense creation». Whereas, within the framework of the second approach the notion «translation» is undergoing the «devaluation» that now stands for the transformation of concepts - their adaption to the world comprehension. The first approach to the problem, as the matter of fact, suggests a variant for the secondary nomination in the given text. The second technique shifts the problem to the sphere of the general theory of the sense creation, in which the interlanguage translation is a certain case for the sense creation of the second level abstraction, and doesn't differ basically from a typical interpretation of the text (in this case, we deal with the one-sided analysis, so called the recipient's perspective). The second prototype demonstrates an example extremely resembling the process of the perception of any discourse type irrespectively of the language it is produced into.

We can make sure, that the both approaches, whatever multidirectional they may seem, have common basis for existing, namely, they try to solve the problem considering the sense of creation and the translation in interpenetration. Thus, they obtain it out of the translation object of the research. It follows that, to be in the field of linguistics and the theory of translation, to examine and to determine the correlation of the translation and the sense creation within the framework of these sciences, it is important to consider both the translation (the interlingual translation) and the sense creation (a chance of coordination and reproduction of language signs in the form of the discourse) as relatively self-dependent objects of studying and having possible centres of correlation.
Origination of the discourse of any kind and its translation are the processes, gaining different subjects but one object. The processes are different in their direction ("towards the object" and "from the object" correspondently), but they can be met in a text-object, which comes to form ontological supposition for the objectiveness of the translation. However, it's worth mentioning that in case the aim of the producer is to create the discourse, the aim of the recipient is to fill it with sense. Another important factor of possible objectivized and adequate translability is linearity of the text as a material creation. The idea of the producer is reflected in this linear creation; the only primary reality for an interpreter/recipient will be the linear text read for the first time, but not the initial idea, nor the presence of systematic and structural sense, only the text created by the author. Apparently, the linear character of perception coexists with its over-linear character in the mind of the interpreter. Just such unity and contradiction of the two provides the fruitful tension in the perception of the text, which, in its turn, is regarded as the base for the sense creation for the recipient.

In regard to the sense formation (both in the origination and perception), the specific characteristics of feature and philosophic discourse, which lays in the sphere of our special scientific interest, is in the producer and the recipient's orientation of obviousness and homogeneity of the sense lacking.

Linguoculturally and conceptually marked elements of the text stand for the means of the sense realization of the discourse in the linear environment. The significant role of linguocultural and "game" strategies in the process of origination and interpretation of the discourse is undoubtful. They are the very means for the author to create "sense gaps" (the term of N.I. Zhinkin), or some occasional innovations, which are of great importance in the structural construction of the discourse (in this case the structure is meant as an interrelation of functional elements of the system, which occur on all its levels). The role of the innovations can be compared with the role of codes and passwords, which are impossible to be revealed by the recipient in some databases, and as a result, he has to decode them indirectly. In the process of multi-variability and uncertainty there comes the role of conceptual components of special importance, which are able to form the over-linear structure on the level of the perception of the text as an integral unity and, as it is believed, can play the key role in the sense volume creation. While creating the structure, the recipient might face some difficulties, but it only emphasizes the value of the over-linear structure to reach an adequate translation.

Now let us view the phenomenon from the translation point of view. The main goal of the translation is the creation of a secondary discourse in the language of the translation on the base of its translation analysis in the original language, which can replace the original one in another linguocultural environment [7]. Most of the researchers distinguish a biphasic character of the translation process, which is the result of the existence of both original and secondary communicative situations. If make the difference between psychological 
and procedural aspects of the text perception in the original and foreign language slight, the interpreter can be considered to be the recipient, being the primary communicator, who percepts and analyzes the text, as well as transforms "strange" linquocultural and conceptual senses, setting them in a new hierarchical structure according to his view. It is obvious, that in such approach, all mentioned above about the sense reconstruction and its intentional character, about the creation of sense with the possible occurrence of multilateral effect on the level of integrity taken into account, on the base of conceptual/linguocultural analysis of noematic essence and a kind of interaction between similar and factual constituents is applicable enough to the situation of interpretation (perception) of the discourses of different orientation by an interpreter (i.e. to the primary communicative situation). Viewing the secondary communicative situation, when the recipient plays the part of the interpreter, who reconstructs the sense and gains the translated text as factual information, one can say that all the mentioned above about the parameters of the interpretation and the possible ways of sense creation, based on the reconstructed sphere of concepts and linguocultural aspects of new senses raising, are relevant in regard to the secondary communicative situation.

It should be noted that the relevance of the described general parameters of sense creation for both primary and secondary communicative situation does not mean the equivalence of distinct and real sense characteristics of the original and the translated texts. Translation as the process is connected with sense, constructed by the interpreter; nevertheless, the translation goes far beyond the limits of sense, it comes back towards the discourse but it is the discourse of the other kind, secondary and reflected one. Notably, if any errors of the interpreter, touching the reconstruction/decoding of sense creating intentions of the original discourse within the process of conscious perception can be considered as unwarranted subjectivism and the extension of the periphery zones to the detriment of its nuclear ones is not still formalized, they gain the material realization in the targeted discourse. For the reader-interpreter of the translated text, the one is the only factual reality (except for bilinguals, where we are to recognize the recipient's belonging to both cultural communities) and he can't and doesn't judge any sense shifts, being the result of the translation, apart from some evident logical and semantic discrepancies. All the facts cause the devaluation of the targeted discourse for the research of the ways of sense creation (the author's sense creation is meant here).

Let us turn to the point of Sinnesverschiebung effect in the process of noematic realities construction. The degree of some kind (in some cases it is the highest one), Sinnesverschiebung effect, taking place while the reception, inevitably accompanies the process of translation. Texts of autotranslation can serve as an illustration of this point of view, i.e. the translation of his own texts by the author and the comparison of the original and so-called reverse translation, as well as the translations of one and the same text, made by different interpreters (we faced the ones while studying
Heidegger's original texts and their translations, made by V.V. Bibichin. We can evidently speak about personal, linguistic and linguocultural inference while transfer of conceptual and linguocultural information of the discourse, though the strict boundary between them can hardly be determined (personal transfer is made by using the facilities of the targeted language, being applied; the choice of the facilities while the transferring of the primary intentional sense is undoubtedly influenced by personal preferences of the recipient-interpreter; the interpreter's perception of the world has an effect on conceptual and linguocultural information, the latter is based on potential linguistic resource). The role of occasional elements in the text is of great importance (it touches the philosophic discourse in particular, where Heidegger's works can serve as an example). Qualitative character of the transfer in the perception and the translation of the multidirectional discourses shapes its qualities and reveals positive and negative sides. "Objectively adequate" text of the translation (i.e. based on the rules and possibilities of the targeted language, without entering the "language at the border and beyond its boundaries" level) may not correspond with "thinking" constructions themselves, which are taken from the original by the recipient-interpreter, just as the original in its material form may deviate from the idea of its direct author; the text of the original and the text of the translation are of the linear character in the reality, as it has been mentioned above, while the idea and the sense have extensional features. At the same time, the translated text, made according to the classical rules (without the theory of functional system applied), has a less potential of variability and arbitrariness than a mental sense construction, which occur as the result of the one, made by an interpreter, being acquainted with linguocultural and conceptual sense of the objective language. As such verbalized abstract thinking construction is free from the necessity of interpreting the original idea, influenced by secondary explicit artistic, stylistic and conceptual form, aimed at maximal reaching of the original one, expressiveness and objectiveness serve to be the most important quality of linguocultural transfer, the ones which occur inevitably, despite the dominant "subjective" nature of the interfering process itself (gaining the possibilities and the structure of the targeted language). It is obvious, that the problem of sense concentration per one language unit can be determined through the correspondence between the original and translated texts volume. On the other hand, there exists the opinion that careful formal following the original in the process of translation doesn't prevent mistakes, provided the fact that there may occur some lack of diversified (linguistic and conceptual) sense effects. Unjustified formalism can be also viewed as negative, but, in this case, as backward-directed language interference. Precise transfer of the diversified sense effects can be reached through exercising of challenging, informal translation techniques, which allow some inaccuracy in the equivalence on the low levels in order to reach the equivalence on the higher ones; such decisions should be regarded as the form of non-automatic positive interference manifestation. 
If we consider different interpretations of the concept "adequacy" of the translation, we will observe different criteria of the notion. Evidently, we can render it as the sort of the correspondence between the original and translated text, with the main aim of the translation taken into account, on condition that the translation is viewed as the process; in this connection we will try to put forward another criteria of the adequacy (with due regard to the similarity between sensecreative and interpretative activity of the interpreter). The criteria is to transfer the effects of conceptual and linguocultural sense diversity on the level of the integral text, the effects, which raise as the result of the assimilation of the text representation on the level of linear integrity and on the extentional one. This is the criteria of extremely possible (without breaking the stylistic norms of the targeted language) preserving of a linguocultural and conceptual sense constituent, the criteria of successful reproduction of the original text by means of the targeted language. The sphere of concepts and linguocultural aspect, their structure of over-linear advance can serve as the main basic components, which are to be analyzed due to the perception and comparison of the original text and the translation. Special attention should be paid to the degree of evident expressiveness of the components in the translation, to the character of the interaction between the structure of linguocultural and conceptual essence and the factual constituent, as well as to the balance of the elements within the conceptual structure, mentioned above. However, it is necessary to recognize the importance of the compensation, or non-automatic positive interference just on the level of this structure transfer. So as for the sense derivation and interpretation question within the third abstraction reflection text we should say that it is "kein bloßes Vorurteil" [8] (not a definitive verdict).

In our view, such approach is valuable enough both for the translation science and for the linguistics in a whole. The consideration of linguocultural and conceptual multivariable sense structures seems to be justified in the translation of philosophic discourses, considered to be difficult to reveal the sense of.

"The things which are turned into entertaining reading are not at all wolfian logics, methaphysics or ethics: they are just the speculation about common matters, the base of which derived from the system. The system, created by a philosopher, if it is really based on the speculative principles and educed from them with the systematic thoroughness, cannot be explicated without the help of an artificial language and this is the fact which makes it impossible to be simplified for public reading. Only universally beneficial results of the systems can be turned into a la portu de tout le monde by expedient intellect. Lichtenberg's telling about the sky is an absorbing reading for everyone and seems to be meant as a pocket book. But still it is the result of a great number of deep analysis and estimation, which couldn't have been made easy-to-read and entertaining works by the author himself much as he would like to" [9].
Some difficulties in the interpretation of philosophic texts compose their value, raising thinking and reflection; true philosophic language requires effort of a special kind. In the introductory article to Hegel-Lexicon Glockner writes: "It's common knowledge that Hegel uses his own language and this is the reason why his works are to be read, just as the ones of medieval or ancient philosophy, with the very "philological" devotion to the language, which is not the one to be commonly understood" [10].

All this let us draw the conclusion that the character of the interpreting perception of the structure can be applied both to the nuclear and periphery parts of the sense creation; notably, the more optimized the interpretation will be respectively the sense centre in the translation, the higher the degree of correlation or correspondence will be observed between the nuclear sense zone of primary and the nuclear sense zone of secondary sense creation.

\section{Results and Discussion}

Discourse records certain fragments of the objective reality, takes down the spheres of the reflection, but philosophic text distributes the senses and acquits the being from the field of textual reality, as if restructures the discourse. A significant gap between intuitively realized and verbalized in a philosophic text is the misunderstanding, which is the base for the thought and it serves to be the major factor of phenomenological reflection formation. As for sense building, the specific feature of philosophic discourse lays in both the producer and the recipient lacking in the set for the evidence and homogeneity of the sense.

The mechanism of a philosophic reflection is stipulated by the borders of the certain conceptual unities, individual, linguocultural and universal ones, rather than the borders of the language. The instrument of thinking without a sensuous address to the studying of the facts can be applied in the case the fact coincides with eidos. Denotation or substantialization is essential, but not dominating in the construction of definitions for functional concepts. It is preceded by the operation of image creation, based on the sense perception.

Findings: An increased studying interest in philosophic texts of existentialism, being observed recently, is stipulated by the universal significance of this system of philosophizing, as well as the similarity of this type of thinking with the proper hermeneutic one, based on the linquoculture of a different, hieroglyphic type; due to the fact it is possible to demonstrate the phenomenon of sense creation in the "irregular" for the traditional philosophy syncretical forms.

The studying appears to be the important step towards the creation of reasonable, sound and universal for different cultures sense theory of philosophic discourse; we are sure that the results of the research can be helpful for revealing the common principles of the texts creation, working out the classification of transformational models of the rethinking superstructure, 
which is most demanding currently, and introducing non-usual philosophic concepts.

\section{References}

1. K. Jaspers, Der philosophische Glaube (Piper. Ungekürzte Taschenbuchausg, München, 2012)

2. J. Habermas, Der Philosophische Diskurs der Moderne. Zwölf Vorlesungen (Suhrkamp Verlag, Frankfurt am Main, 1985)

3. V. Fartov, Philosophy as pseudodiscourse [Electronic resource]. URL: http://netess.ru/3knigi/869273-1-vtfaritov-filosofiyakak-psevdodiskurs-cel-predlagaemoy-stati-datotvet-vopros-kotoriy-uzhe-raz-sta-vilsyanahodil.php
4. S. Bredikhin, Noematic hierarchy of philosophic text in respect of the aspect of sense derivation and interpretation (RIO IDNK, Stavropol, 2014)

5. M. Mamardashvili, How I take the meaning of philosophy (Progress, Moscow, 1990)

6. D. Psurtsev, Translation and discourse, Vestnik MGLU 463, 16-26 (2002)

7. A. Shveytser, Translation theory: Status, problems, aspekts (Nauka, Moscow, 1988)

8. B. Smith Zur Nichtübersetzbarkeit der deutschen Philosophie, Zur philosophischen Aktualität Heideggers 3, 125-147 (Frankfurt am Main, Vittorio Klostermann, 1992)

9. G. Fülleborn, Beiträge zur Geschichte der Philosophie 1-2 (Onix, Moscow, 2012)

10. H. Glockner, Hegel-Lexikon 1-4 (Stuttgart, 1934)

* Corresponding author: bredichinsergey@yandex.ru 